\title{
Polymorphisms of genes coding for ghrelin and its receptor in relation to colorectal cancer risk: a two-step gene-wide case-control study
}

\author{
Daniele Campa ${ }^{1,2^{*}}$, Barbara Pardini ${ }^{3}$, Alessio Naccarati ${ }^{3}$, Ludmila Vodickova ${ }^{3}$, Jan Novotny ${ }^{4}$, Verena Steinke ${ }^{5}$, \\ Nils Rahner ${ }^{5}$, Elke Holinski-Feder ${ }^{6}$, Monika Morak ${ }^{6}$, Hans K Schackert ${ }^{7}$, Heike Görgens ${ }^{7}$, Judith Kötting ${ }^{8}$, Beate Betz ${ }^{9}$, \\ Matthias Kloor ${ }^{10}$, Christoph Engel ${ }^{11}$, Reinhard Büttner ${ }^{12}$, Peter Propping ${ }^{5}$, Asta Försti ${ }^{1,13}$, Kari Hemminki ${ }^{1,13}$, \\ Roberto Barale ${ }^{2}$, Pavel Vodicka ${ }^{3}$, Federico Canzian ${ }^{1}$
}

\begin{abstract}
Background: Ghrelin, an endogenous ligand for the growth hormone secretagogue receptor (GHSR), has two major functions: the stimulation of the growth hormone production and the stimulation of food intake. Accumulating evidence also indicates a role of ghrelin in cancer development.

Methods: We conducted a case-control study to examine the association of common genetic variants in the genes coding for ghrelin (GHRL) and its receptor (GHSR) with colorectal cancer risk. Pairwise tagging was used to select the 11 polymorphisms included in the study. The selected polymorphisms were genotyped in 680 cases and 593 controls from the Czech Republic.

Results: We found two SNPs associated with lower risk of colorectal cancer, namely SNPs rs 27647 and rs35683. We replicated the two hits, in additional 569 cases and 726 controls from Germany.

Conclusion: A joint analysis of the two populations indicated that the T allele of rs27647 SNP exerted a protective borderline effect $\left(P_{\text {trend }}=0.004\right)$.
\end{abstract}

\section{Background}

Ghrelin, an endogenous ligand for the growth hormone secretagogue receptor (GHSR), is a 28-amino residue peptide predominantly produced by the stomach [1]. In addition to the mature form of ghrelin, several posttranscriptional and post-translational variants have been reported [2]. Two molecular forms (ghrelin and des-acyl ghrelin) resulting from a different post-transcriptional modification of the protein, are observed in human plasma. The ghrelin receptor has two known isoforms: one which is functional (GHSR-1a) and one spliced variant (GHSR-1b) with no known function [3]. Only the acylated form of ghrelin can bind the GHSR-1a receptor [1]. Two main functions of ghrelin are documented: first to stimulate growth hormone $(\mathrm{GH})$ production through

\footnotetext{
* Correspondence: d.campa@dkfz.de

'Genomic Epidemiology Group, German Cancer Research Center (DKFZ), Im Neuenheimer Feld 280, D-69120 Heidelberg, Germany

Full list of author information is available at the end of the article
}

the activation of the GHSR-1a in the hypothalamus [4] and second to increase appetite and food intake $[5,6]$ by mechanisms that could be independent of GHSR [7].

Circulating ghrelin levels are correlated with obesity, and insulin may be an important regulator of plasma ghrelin levels in different states of nutrition [8-11]. Several studies of different populations have shown that levels of ghrelin are related to body size [12], although its mode of action as a regulator of body fat stores remains unclear [12]. Obesity induces a number of metabolic disturbances known as the metabolic syndrome, and is associated with an excess risk of insulin resistance, diabetes, and cardiovascular disease [13-15].

Obesity and related metabolic abnormalities are consistent risk factors for CRC [16]. In most studies, obesity (measured as BMI, waist circumference or waist-to-hip ratio) is associated with a relative risk of 1.5 to 2.0 compared with a low or normal BMI [17-20]. Similarly, associations for circumference measures have been noted for 
large or advanced adenoma, the proximate precursor to most colon cancers $[19,21,22]$. Overall, the data strongly support that some metabolic characteristics associated with central or abdominal adiposity increases risk of CRC.

Accumulating evidence also indicate a role of ghrelin in cell proliferation, inhibition of apoptosis and cancer development [23-26].

Polymorphisms in the coding region of the ghrelin gene were suggested to be involved in the aetiology of obesity and to modulate glucose-induced insulin secretion in different ethnic study groups [27]. Hence, variations in the ghrelin gene influencing the expression and/ or function of the ghrelin protein might alter energy balance, contribute to obesity and, indirectly, to CRC risk. We postulate that Single Nucleotide Polymorphisms (SNPs) in the genes coding for ghrelin and its receptor maybe associated with an altered risk of CRC.

In this report we investigated the genetic variability of the GHRL and GHSR genes. Using a tagging approach and selecting 7 SNPs in GHRL gene and 4. SNPs in the GHSR gene we covered all the known genetic variation of the two genes. We tested the impact of GHRL and GHSR SNPs on CRC risk in a case-control study based on subjects from the Czech Republic. In a second step we replicated the best associations in an unrelated German population. To our knowledge this is the first report on polymorphisms of GHRL, GHSR and CRC risk.

\section{Methods}

\section{Study populations}

In this study we have used two distinct populations: one from Czech Republic and the other from Germany. All SNPs were typed in the Czech population while only two SNPs showing an altered risk of CRC in the first population were typed in the German cases and controls.

\section{Czech population}

The population has been extensively described elsewhere $[28,29]$. Briefly: cases were CRC patients visiting nine oncological departments (two in Prague, one each in Benesov, Brno, Liberec, Ples, Pribram, Usti nad Labem, and Zlin) distributed in all geographic regions of Czech Republic and being representative of the population of the entire country. This study includes 680 patients who could be interviewed and provided biological samples of sufficient quality for genetic analysis. All cases had histological confirmation of their tumor diagnosis.

Controls were selected among patients admitted to five large gastroenterological departments (Prague, Brno, Jihlava, Liberec, and Pribram) all over the Czech Republic, during the same period of the recruitment of cases.
Selected controls were all of Czech Caucasian origin. Only subjects whose colonoscopic results were negative for malignancy, colorectal adenomas or IBD were chosen as controls. Among 739 invited controls, a total of 593 $(80.2 \%)$ were analyzed in this study (lost controls were similar to those included with respect to sex distribution).

Cases included in this study had a mean age of 61 years (range 27-90), while controls had a mean age of 56 years (range 28-91). Study subjects provided information on their lifestyle habits (smoking, drinking, diet etc.), and family/personal history of cancer, with the use of structured questionnaires.

The genetic analyses did not interfere with diagnostic or therapeutic procedures for the subjects. All participants signed an informed written consent and the design of the study was approved by the Ethical Committee of the Institute of Experimental Medicine, Prague, Czech Republic.

\section{German population}

CRC cases comprised 569 German Caucasian index patients (age range 9-88 years, mean 43.6 years) recruited by the six German university hospitals of Bochum (BO), Bonn (BN), Dresden (DD), Düsseldorf (DÜ), Heidelberg (HD) and Munich/Regensburg (MR). Cases were collected as part of a large study on susceptibility to hereditary nonpolyposis CRC (HNPCC). Inclusion criteria for the cases were (i) a family history of CRC or (ii) CRC diagnosed under the age of 50. Analysis for microsatellite instability was applied as a pre-screening test prior to mutation analysis in the MSH2 and MLH1 genes. All cases were tested to be microsatellite stable.

The control series consisted of 726 healthy, unrelated, sex-and age matched blood donors (26-68 years, mean 45.9 years) which were recruited between 2004 and 2006 by the Institute of Transfusion Medicine and Immunology, Faculty of Mannheim, Germany. The matching intervals for age were 'younger than 30 years', five-year groups (30-34, 35-39, ..., 60-64) and 'older than 65 years'. Blood sampling was performed during regular blood donation according to German guidelines. Selected controls were all of German Caucasian origin. The study was approved by the competent local Ethics Committees, and written informed consent was obtained from all individuals.

\section{Selection of tagging SNPs}

We aimed at surveying the entire set of common genetic variants in the GHRL and GHSR genes. For this purpose, we used the Tagger algorithm [30] that was developed to select maximally informative sets of tagSNPs in candidate-gene association study. All polymorphisms in the region of the two genes of interest with minor allele frequency (MAF) $\geq 5 \%$ in Caucasians 
from the International HapMap Project (version 22; http://www.hapmap.org), were included. Tagging SNPs were selected with the use of the Tagger program within Haploview http://www.broad.mit.edu/mpg/haploview/; http://www.broad.mit.edu/mpg/tagger/[31,32], using pairwise tagging with a minimum $\mathrm{r}^{2}$ of 0.8 .

This resulted in a selection of 11 tagging SNPs, 7 for the GHRL gene (with a mean $\mathrm{r}^{2}$ of the selected SNPs with the SNPs they tag of 0.967), and 4 for the GHSR gene (with an $\mathrm{r}^{2}$ of 0.989 ). Our selection thus captures to a very high degree the known common variability in this gene.

\section{DNA extraction and genotyping}

DNA was extracted from blood samples with standard proteinase $\mathrm{K}$ digestion followed by phenol/chloroform extraction and ethanol precipitation. The order of DNAs from cases and controls was randomized on PCR plates in order to ensure that an equal number of cases and controls could be analyzed simultaneously. All the genotyping was carried out using the Taqman assay, according to manufacturer's protocol. The pre-designed Taqman assays were purchased from Applied Biosystems (Foster City, CA).

All samples that did not give a reliable result in the first round of genotyping were resubmitted to up to two additional rounds of genotyping. Data points that were still not filled after this procedure were left blank. Repeated quality control genotypes ( $8 \%$ of the total) showed an average concordance of $99.5 \%$.

\section{Statistical Analysis}

The frequency distribution of genotypes was examined for the cases and the controls. Hardy-Weinberg equilibrium was tested in the cases and in the controls separately by chi square test. We used logistic regression for multivariate analyses to assess the main effects of the genetic polymorphism on CRC risk using a codominant inheritance model. The most common allele in the controls was assigned as the reference category. All analyses were adjusted for age and sex.

Additionally, we performed a logistic regression stratifying for the cancer site (colon versus rectum) and smoking (smokers versus non smokers and heavy smokers versus light smokers) or alcohol drinking (drinkers vs. non-drinkers) habits.

For SNPs rs27647 and rs35683 the analysis were performed in the two populations. Odds ratios were calculated for the two populations separately and jointly.

All the analyses were performed with STATA software (StataCorp, College Station, TX).

\section{Results}

We performed a case-control study using two different sets of SNPs in two distinct populations of German and
Czech origins. The first SNP set was made of 11 tagging SNPs which we tested in 680 cases and 593 controls from the Czech Republic. The second SNP set consisted of the two best hits, namely SNPs rs27647 and rs35683, which we replicated in additional 569 cases and 726 controls from Germany. The genotype frequencies among the controls were in Hardy-Weinberg equilibrium for all the SNPs and in both populations.

\section{Results for the Czech population}

The distribution of the genotypes and their odds ratios (ORs) for association with CRC risk are shown in Table 1.

We found that, in this sample set, carriers of the $\mathrm{T}$ allele of SNP rs27647 had a decreased risk of CRC, with an OR of 0.70 (95\% confidence interval (95\% CI) 0.55 $\left.0.91 ; \mathrm{P}_{\text {value }}=0.013\right)$, for $\mathrm{C} / \mathrm{T}$ heterozygous individuals and an OR of 0.57 (95\% CI 0.40-0.80; $\left.\mathrm{P}_{\text {value }}=0.002\right)$ for $\mathrm{T} / \mathrm{T}$ homozygous individuals $\left(\mathrm{P}_{\text {trend }}=0.001\right)$.

Moreover we found that carriers of the $\mathrm{C}$ allele of SNP rs35683 had a decreased risk of CRC, with an OR of0.71 (95\% CI 0.51-0.98; $\mathrm{P}_{\text {value }}=0.04$ ) for C/C homozygous individuals. The OR of 0.80 for the heterozygous individuals was not statistically significant (95\% CI 0.60 $\left.1.05 ; \mathrm{P}_{\text {value }}=0.42\right)\left(\mathrm{P}_{\text {trend }}=0.02\right)$.

We did not find any statistically significant association between the other SNPs and CRC risk.

\section{Results for the German population}

The distribution of the genotypes and their odds ratios (ORs) for association with CRC risk are shown in Table 2.

The associations found in the Czechs were not confirmed in the German population. However, the effect of SNP rs27647 was statistically significant in a joint analysis of data from the two populations. The carriers of the $T$ allele in the joint group exerted a protective effect, with an OR of 0.82 (95\% CI 0.69-0.98; $\mathrm{P}_{\text {value }}=0.02$ ), for $\mathrm{C} / \mathrm{T}$ individuals and an OR of $0.73\left(95 \%\right.$ CI $0.58-0.93$; $\left.\mathrm{P}_{\text {value }}=0.01\right)$ for $\mathrm{T} / \mathrm{T}$ homozygous individuals $\left(\mathrm{P}_{\text {trend }}=0.0043\right)$.

Applying the Bonferroni correction for multiple testing the $\mathrm{P}_{\text {trend }}$ of $\mathrm{rs} 27647$ in the joint population remained borderline significant $\left(\mathrm{P}_{\text {trend }}=0.0043 \times 11=\right.$ 0.047), although neither the ORs for heterozygotes nor for the homozygotes remained statistically significant after correction. A test for heterogeneity indicated that the results for the two populations were statistically different $\left(\mathrm{P}_{\text {heterogeneity }}=0.014\right)$.

\section{Stratified analysis and interactions}

Analyses stratified by cancer site (colon vs. rectum), alcohol and smoking habits did not show any significant interaction with polymorphisms (data not shown).

We performed analysis stratified by age using the median age as a cut off. In the German population we found no difference in the genotype distribution in the 
Table 1 Associations of GHRL and GHSR polymorphisms with colorectal cancer risk in the Czech population

\begin{tabular}{|c|c|c|c|c|c|}
\hline & Cases $^{a}$ & Controls $^{a}$ & OR(95\%) & $P$ value & $\mathrm{P}$ trend \\
\hline \multicolumn{6}{|l|}{ GHRL } \\
\hline \multicolumn{6}{|c|}{ rs26802 } \\
\hline $\mathrm{G} / \mathrm{G}$ & 286 & 278 & 1 & & \\
\hline $\mathrm{G} / \mathrm{T}$ & 294 & 245 & $1.18(0.92-1.51)$ & 0.18 & \\
\hline $\mathrm{T} / \mathrm{T}$ & 93 & 74 & $1.19(0.82-1.70)$ & 0.25 & 0.16 \\
\hline \multicolumn{6}{|c|}{ rs27647 } \\
\hline$C / C$ & 279 & 198 & 1 & & \\
\hline$C / T$ & 289 & 280 & $0.70(0.55-0.91)$ & 0.008 & \\
\hline $\mathrm{T} / \mathrm{T}$ & 93 & 110 & $0.57(0.40-0.80)$ & 0.002 & 0.001 \\
\hline \multicolumn{6}{|c|}{ rs35683 } \\
\hline $\mathrm{A} / \mathrm{A}$ & 204 & 147 & 1 & & \\
\hline $\mathrm{A} / \mathrm{C}$ & 331 & 297 & $0.80(0.61-1.05)$ & 0.11 & \\
\hline $\mathrm{C} / \mathrm{C}$ & 137 & 143 & $0.71(0.51-0.98)$ & 0.04 & 0.02 \\
\hline \multicolumn{6}{|c|}{ rs4684677 } \\
\hline $\mathrm{A} / \mathrm{A}$ & 601 & 523 & 1 & & \\
\hline $\mathrm{A} / \mathrm{C}$ & 78 & 74 & $0.91(0.64-1.30)$ & 0.49 & \\
\hline $\mathrm{C} / \mathrm{C}$ & 4 & 3 & $1.63(0.35-7.68)$ & 0.62 & 0.70 \\
\hline \multicolumn{6}{|c|}{ rs696217 } \\
\hline G/G & 590 & 523 & 1 & & \\
\hline $\mathrm{G} / \mathrm{T}$ & 84 & 71 & $1.09(0.77-1.55)$ & 0.64 & \\
\hline $\mathrm{T} / \mathrm{T}$ & 4 & 6 & $0.60(0.16-2.18)$ & 0.43 & 0.89 \\
\hline \multicolumn{6}{|c|}{ rs2075356 } \\
\hline C/C & 559 & 498 & 1 & & \\
\hline$C / T$ & 101 & 78 & $1.20(0.86-1.68)$ & 0.63 & \\
\hline $\mathrm{T} / \mathrm{T}$ & 7 & 7 & $0.88(0.30-2.61)$ & 0.36 & 0.28 \\
\hline \multicolumn{6}{|c|}{ rs35684 } \\
\hline A/A & 257 & 248 & 1 & & \\
\hline$A / G$ & 213 & 174 & $1.10(0.84-1.43)$ & 0.46 & \\
\hline $\mathrm{G} / \mathrm{G}$ & 47 & 34 & $1.24(0.77-2.00)$ & 0.36 & 0.29 \\
\hline \multicolumn{6}{|l|}{ GHSR } \\
\hline \multicolumn{6}{|c|}{ rs2922126 } \\
\hline $\mathrm{T} / \mathrm{T}$ & 255 & 20 & 1 & & \\
\hline$A / T$ & 269 & 274 & $0.81(0.62-1.05)$ & 0.11 & \\
\hline $\mathrm{A} / \mathrm{A}$ & 74 & 39 & $1.48(0.95-2.30)$ & 0.82 & 0.31 \\
\hline \multicolumn{6}{|c|}{ rs2944694 } \\
\hline A/A & 564 & 477 & & & \\
\hline$A / G$ & 98 & 101 & $0.78(0.57-1.07)$ & 0.14 & \\
\hline $\mathrm{G} / \mathrm{G}$ & 7 & 11 & $0.46(0.16-1.28$ & 0.14 & 0.08 \\
\hline \multicolumn{6}{|c|}{ rs495225 } \\
\hline A/A & 333 & 293 & 1 & & \\
\hline$A / G$ & 232 & 220 & $0.88(0.68-1.13)$ & 0.33 & \\
\hline $\mathrm{G} / \mathrm{G}$ & 58 & 42 & $1.17(0.75-1.83)$ & 0.47 & 0.77 \\
\hline \multicolumn{6}{|c|}{ rs572169 } \\
\hline C/C & 329 & 305 & 1 & & \\
\hline $\mathrm{C} / \mathrm{T}$ & 263 & 235 & $1.03(0.80-1.31)$ & 0.80 & \\
\hline $\mathrm{T} / \mathrm{T}$ & 57 & 48 & $1.14(0.74-1.74)$ & 0.55 & 0.62 \\
\hline
\end{tabular}

a Numbers may not add up to $100 \%$ of subjects due to genotyping failure. All samples that did not give a reliable result in the first round of genotyping were resubmitted to up to two additional rounds of genotyping. Data points that were still not filled after this procedure were left blank.

${ }^{b} \mathrm{OR}$ : odds ratio; $\mathrm{Cl}$ : confidence interval. Adjusted for age and gender. Results in bold are statistically significant $(p<0.05)$
Table 2 Associations of GHRL polymorphisms with colorectal cancer risk in the German cases and controls

\begin{tabular}{cccccc}
\hline & Cases $^{\mathbf{a}}$ & Controls $^{\mathbf{a}}$ & OR(95\%) & P value & P trend \\
\hline rs27647 GHRL & & & & & \\
C/C & 213 & 259 & 1 & & \\
C/T & 278 & 360 & $0.93(0.73-1.19)$ & 0.60 & \\
T/T & 78 & 107 & $0.83(0.62-1.24)$ & 0.49 & 0.54 \\
\hline rs35683 GHRL & & & & & \\
A/A & 172 & 220 & 1 & & \\
A/C & 277 & 356 & $0.99(0.77-1.28)$ & 0.97 & \\
C/C & 120 & 150 & $0.99(0.72-1.35)$ & 0.95 & 0.99 \\
\hline
\end{tabular}

${ }^{a}$ Numbers may not add up to $100 \%$ of subjects due to genotyping failure. All samples that did not give a reliable result in the first round of genotyping were resubmitted to up to two additional rounds of genotyping. Data points that were still not filled after this procedure were left blank.

b OR: odds ratio; $\mathrm{Cl}$ : confidence interval. Adjusted for age and gender. Results in bold are statistically significant $(p<0.05)$

two population strata concerning cancer risk. For the Czech population we found that only in the older group (age $>66$ ) the homozygous carriers of the variant alleles of two SNPs showed a statistically significant association with cancer risk: OR of $0.39\left(95 \% \mathrm{CI} 0.21-0.73 \mathrm{P}_{\text {value }}=\right.$ $0.003)$ for SNP rs27647 and OR of 0.46 (95\% CI 0.28 $\left.0.78 \mathrm{P}_{\text {value }}=0.004\right)$ for SNP rs35683.

Finally we performed an analysis combining the two polymorphisms in order to assess the impact of cancer risk of a multi-locus risk score, but the results did not explain more of the genetic susceptibility to the disease than the two SNPs alone (data not shown).

\section{Discussion}

Recent evidence indicates that obesity and related metabolic abnormalities are associated with increased incidence and mortality for CRC. Since it has been shown that circulating levels of ghrelin are related to body size we postulated that polymorphisms that could alter protein expression and/or function may also alter CRC risk.

In this study we investigated the genetic variability of the GHRL and GHRS genes in relation to CRC risk using a tagging approach and selecting 11 SNPs. Using this method we covered all the known genetic variation of the genes, an effort lacking from all previous studies.

On the first phase of the project we typed all the 11 tagging SNPs in CRC cases and controls from the Czech Republic and we found that two SNPs (rs27647, rs35683) were associated with a decreased risk of CRC.

SNP rs27647 is situated in the promoter region of the gene and has been found associated with insulin level and obesity [33], while SNP rs35683 is situated in the first intron of the gene and has been found associated with BMI in a Caucasian population[34]. Since BMI, obesity and insulin level are well known risk factors for CRC, the two SNPs may indirectly affect cancer risk. We sought to replicate these findings in an independent 
group and we used a German population with a similar sample size. In this second population the findings were not replicated.

There are two possible explanations for these findings: either the associations observed from the Czech population are false positives, or the differences in the association results are due to differences between the two selected populations. We can confidently exclude a major role of ethnic differences. According to Globocan [35-37], the Czech and the German populations have a comparable CRC incidence. Moreover in a recent study Nelis and colleagues investigated the underlying population stratification in Europe showing that there were very little, if any, differences in the genetic make-up of Germans and Czechs [38]. Another explanation for the inconsistent findings may be due to different environmental factors in the two countries. However dietary habits and food intake are not dramatically different in the two countries http://faostat.fao.org/site/609/DesktopDefault.aspx?PageID $=609$. It has to be noted that the German subjects were on average young and had a family history of CRC, whereas the Czech cases were unselected.. It may be speculated that genetic predisposition to familial and sporadic cases is due to groups of genetic variants that do not overlap entirely. According to this hypothesis, rs27647 could be more relevant for sporadic cases but not for familial ones. In addition if ghrelin acts indirectly through the effects of increased BMI, Germans subjects may not have been old enough to have had sufficient exposure to increased BMI to show the increased incidence of cancer. In fact, when we stratified the analysis for age groups, only in the older patients the observed association remained significant. Finally, it has not to be overlooked that ORs for rs27647 were similar in the two groups, but the effect does not reach statistical significance in the Germans,. This may indicate that the association could be true, and a larger, independent study is needed to confirm or disproof this finding.

\section{Conclusion}

In conclusion, we are not able to completely exclude a possible effect of the rs27647 SNP in CRC risk, while we can confidently exclude a major role for the other common SNPs in GHRL and GHSR as CRC risk factors.

\footnotetext{
Acknowledgements

The authors would like to thank Mrs. Angelika Stein for her expert technical assistence. The study was partially supported by grant GACR 310/05/2626 from the Grant Agency of the Czech Republic. The remaining financial support was provided by the intramural DKFZ budget.
}

\section{Author details}

${ }^{1}$ Genomic Epidemiology Group, German Cancer Research Center (DKFZ), Im Neuenheimer Feld 280, D-69120 Heidelberg, Germany. ${ }^{2}$ Department of
Biology, University of Pisa, Pisa, Italy. ${ }^{3}$ Institute of Experimental Medicine, Academy of Sciences of the Czech Republic, Prague, Czech Republic. ${ }^{4}$ Department of Oncology, First Faculty of Medicine, Charles University, Prague, Czech Republic. Institute of Human Genetics, University of Bonn, Bonn, Germany. 'Department of Internal Medicine, Campus Innenstadt, University Hospital of Ludwig-Maximilians-University, Munich, Germany. ${ }^{7}$ Department of Surgical Research, Technische Universität Dresden, Dresden, Germany. ${ }^{8}$ Medical Department, Knappschaftskrankenhaus, Ruhr University, Bochum, Germany. ${ }^{9}$ Institute of Human Genetics, University of Düsseldorf, Düsseldorf, Germany. ${ }^{10}$ Department of Applied Tumour Biology, Institute of Pathology, University of Heidelberg, Heidelberg, Germany. ${ }^{11}$ Institute of Medical Informatics, Statistics and Epidemiology, University of Leipzig, Leipzig, Germany. ${ }^{12}$ Institute of Pathology, University of Bonn, Bonn, Germany. ${ }^{13}$ Center for Primary Health Care Research, Clinical Research Center, Lund University, Malmö, Sweden.

\section{Authors' contributions}

DC conceived the study, carried out the genotyping the statistical analysis and drafted the manuscript, FC supervised the genotyping and the SNPS selection, VS, NR, EH-F, MM, HS HG, JK, BB, MK, CE, RB, PP, PV, BP, AN, MC, $L V$, JN enrolled the subjects of the study and helped in the manuscript writing, KH, RB, AF helped in writing the manuscript. All authors read and approved the manuscript.

\section{Competing interests}

The authors declare that they have no competing interests.

Received: 14 April 2010 Accepted: 28 September 2010 Published: 28 September 2010

\section{References}

1. Kojima M, Hosoda H, Date Y, Nakazato M, Matsuo H, Kangawa K: Ghrelin is a growth-hormone-releasing acylated peptide from stomach. Nature 1999, 402:656-660.

2. Gualillo O, Lago F, Casanueva FF, Dieguez C: One ancestor, several peptides post-translational modifications of preproghrelin generate several peptides with antithetical effects. Mol Cell Endocrinol 2006, 256:1-8

3. Howard AD, Feighner SD, Cully DF, Arena JP, Liberator PA, Rosenblum Cl, Hamelin M, Hreniuk DL, Palyha OC, Anderson J, et al: A receptor in pituitary and hypothalamus that functions in growth hormone release. Science 1996, 273:974-977.

4. van der Lely AJ, Tschop M, Heiman ML, Ghigo E: Biological, physiological, pathophysiological, and pharmacological aspects of ghrelin. Endocr Rev 2004, 25:426-457.

5. Wren AM, Seal LJ, Cohen MA, Brynes AE, Frost GS, Murphy KG, Dhillo WS, Ghatei MA, Bloom SR: Ghrelin enhances appetite and increases food intake in humans. J Clin Endocrinol Metab 2001, 86:5992.

6. Nakazato M, Murakami N, Date Y, Kojima M, Matsuo H, Kangawa K, Matsukura S: A role for ghrelin in the central regulation of feeding. Nature 2001, 409:194-198.

7. Toshinai K, Yamaguchi H, Sun Y, Smith RG, Yamanaka A, Sakurai T, Date Y, Mondal MS, Shimbara T, Kawagoe T, et al: Des-acyl ghrelin induces food intake by a mechanism independent of the growth hormone secretagogue receptor. Endocrinology 2006, 147:2306-2314.

8. Broglio F, Arvat E, Benso A, Gottero C, Muccioli G, Papotti M, van der Lely AJ, Deghenghi R, Ghigo E: Ghrelin, a natural GH secretagogue produced by the stomach, induces hyperglycemia and reduces insulin secretion in humans. J Clin Endocrinol Metab 2001, 86:5083-5086.

9. Cummings DE, Purnell JQ, Frayo RS, Schmidova K, Wisse BE, Weigle DS: A preprandial rise in plasma ghrelin levels suggests a role in meal initiation in humans. Diabetes 2001, 50:1714-1719.

10. Shiiya T, Nakazato M, Mizuta M, Date Y, Mondal MS, Tanaka M, Nozoe S, Hosoda H, Kangawa K, Matsukura S: Plasma ghrelin levels in lean and obese humans and the effect of glucose on ghrelin secretion. J Clin Endocrinol Metab 2002, 87:240-244.

11. Tschop M, Weyer C, Tataranni PA, Devanarayan V, Ravussin E, Heiman ML: Circulating ghrelin levels are decreased in human obesity. Diabetes 2001, 50:707-709. 
12. Langenberg C, Bergstrom J, Laughlin GA, Barrett-Connor E: Ghrelin and the metabolic syndrome in older adults. J Clin Endocrinol Metab 2005, 90:6448-6453.

13. Bosello O, Zamboni M: Visceral obesity and metabolic syndrome. Obes Rev 2000, 1:47-56.

14. Lamarche B: Abdominal obesity and its metabolic complications: implications for the risk of ischaemic heart disease. Coron Artery Dis 1998, 9:473-481

15. Nakamura T, Tokunaga K, Shimomura I, Nishida M, Yoshida S, Kotani K, Islam AH, Keno Y, Kobatake T, Nagai Y, et al: Contribution of visceral fat accumulation to the development of coronary artery disease in nonobese men. Atherosclerosis 1994, 107:239-246.

16. Giovannucci E: Insulin, insulin-like growth factors and colon cancer: a review of the evidence. J Nutr 2001, 131:3109S-3120S

17. Bostick RM, Potter JD, Kushi LH, Sellers TA, Steinmetz KA, McKenzie DR, Gapstur SM, Folsom AR: Sugar, meat, and fat intake, and non-dietary risk factors for colon cancer incidence in lowa women (United States). Cancer Causes Control 1994, 5:38-52.

18. Giovannucci E, Ascherio A, Rimm EB, Colditz GA, Stampfer MJ, Willett WC: Physical activity, obesity, and risk for colon cancer and adenoma in men. Ann Intern Med 1995, 122:327-334.

19. Giovannucci E, Colditz GA, Stampfer MJ, Willett WC: Physical activity, obesity, and risk of colorectal adenoma in women (United States). Cancer Causes Control 1996, 7:253-263.

20. Schoen RE, Tangen CM, Kuller LH, Burke GL, Cushman M, Tracy RP, Dobs A, Savage PJ: Increased blood glucose and insulin, body size, and incident colorectal cancer. J Natl Cancer Inst 1999, 91:1147-1154.

21. Otake S, Takeda H, Suzuki Y, Fukui T, Watanabe S, Ishihama K, Saito T, Togashi H, Nakamura T, Matsuzawa Y, Kawata S: Association of visceral fat accumulation and plasma adiponectin with colorectal adenoma: evidence for participation of insulin resistance. Clin Cancer Res 2005, 11:3642-3646.

22. Shinchi K, Kono S, Honjo S, Todoroki I, Sakurai Y, Imanishi K, Nishikawa H, Ogawa S, Katsurada M, Hirohata T: Obesity and adenomatous polyps of the sigmoid colon. Jpn J Cancer Res 1994, 85:479-484.

23. Baldanzi G, Filigheddu N, Cutrupi S, Catapano F, Bonissoni S, Fubini A Malan D, Baj G, Granata R, Broglio F, et al: Ghrelin and des-acyl ghrelin inhibit cell death in cardiomyocytes and endothelial cells through ERK1/ 2 and PI 3-kinase/AKT. J Cell Biol 2002, 159:1029-1037.

24. Cassoni P, Ghe C, Marrocco T, Tarabra E, Allia E, Catapano F, Deghenghi R, Ghigo E, Papotti M, Muccioli G: Expression of ghrelin and biological activity of specific receptors for ghrelin and des-acyl ghrelin in human prostate neoplasms and related cell lines. Eur J Endocrinol 2004, 150:173-184.

25. Jeffery $\mathrm{PL}$, Herington $\mathrm{AC}$, Chopin LK: The potential autocrine/paracrine roles of ghrelin and its receptor in hormone-dependent cancer. Cytokine Growth Factor Rev 2003, 14:113-122.

26. Yeh AH, Jeffery PL, Duncan RP, Herington AC, Chopin LK: Ghrelin and a novel preproghrelin isoform are highly expressed in prostate cancer and ghrelin activates mitogen-activated protein kinase in prostate cancer. Clin Cancer Res 2005, 11:8295-8303.

27. Bing C, Ambye L, Fenger M, Jorgensen T, Borch-Johnsen K, Madsbad S, Urhammer SA: Large-scale studies of the Leu72Met polymorphism of the ghrelin gene in relation to the metabolic syndrome and associated quantitative traits. Diabet Med 2005, 22:1157-1160.

28. Campa D, Pardini B, Naccarati A, Vodickova L, Novotny J, Forsti A Hemminki K, Barale R, Vodicka P, Canzian F: A gene-wide investigation on polymorphisms in the $A B C G 2 / B R C P$ transporter and susceptibility to colorectal cancer. Mutat Res 2008, 645:56-60.

29. Campa D, Vodicka P, Pardini B, Novotny J, Forsti A, Hemminki K, Barale R, Canzian F: Could polymorphisms in ATP-binding cassette $\mathrm{C} 3$ /multidrug resistance associated protein 3 (ABCC3/MRP3) modify colorectal cancer risk? Eur J Cancer 2008, 44:854-857.

30. Carlson CS, Eberle MA, Rieder MJ, Yi Q, Kruglyak L, Nickerson DA: Selecting a maximally informative set of single-nucleotide polymorphisms for association analyses using linkage disequilibrium. Am J Hum Genet 2004, 74:106-120

31. Barrett JC, Fry B, Maller J, Daly MJ: Haploview: analysis and visualization of LD and haplotype maps. Bioinformatics 2005, 21:263-265.

32. de Bakker PI, Yelensky R, Pe'er I, Gabriel SB, Daly MJ, Altshuler D: Efficiency and power in genetic association studies. Nat Genet 2005, 37:1217-1223.
33. Gueorguiev M, Lecoeur C, Meyre D, Benzinou M, Mein CA, Hinney A, Vatin V, Weill J, Heude B, Hebebrand J, et al: Association studies on ghrelin and ghrelin receptor gene polymorphisms with obesity. Obesity (Silver Spring) 2009, 17:745-754.

34. Chung WK, Patki A, Matsuoka N, Boyer BB, Liu N, Musani SK, Goropashnaya AV, Tan PL, Katsanis N, Johnson SB, et al: Analysis of 30 genes (355 SNPS) related to energy homeostasis for association with adiposity in European-American and Yup'ik Eskimo populations. Hum Hered 2009, 67:193-205.

35. Ferlay JSH, Bray F, Forman D, Mathers C, Parkin DM: GLOBOCAN 2008, Cancer Incidence and Mortality Worldwide: IARC CancerBase No. 102008.

36. Ferlay J, Parkin DM, Steliarova-Foucher E: Estimates of cancer incidence and mortality in Europe in 2008. Eur J Cancer 2010, 46:765-781.

37. Ferlay J, Shin HR, Bray F, Forman D, Mathers C, Parkin DM: Estimates of worldwide burden of cancer in 2008: GLOBOCAN. Int J Cancer 2008.

38. Nelis M, Esko T, Magi R, Zimprich F, Zimprich A, Toncheva D, Karachanak S, Piskackova T, Balascak I, Peltonen L, et al: Genetic structure of Europeans: a view from the North-East. PLoS One 2009, 4:e5472.

\section{Pre-publication history}

The pre-publication history for this paper can be accessed here: http://www.biomedcentral.com/1471-230X/10/112/prepub

doi:10.1186/1471-230X-10-112

Cite this article as: Campa et al:: Polymorphisms of genes coding for ghrelin and its receptor in relation to colorectal cancer risk: a two-step gene-wide case-control study. BMC Gastroenterology 2010 10:112.

\section{Submit your next manuscript to BioMed Central and take full advantage of:}

- Convenient online submission

- Thorough peer review

- No space constraints or color figure charges

- Immediate publication on acceptance

- Inclusion in PubMed, CAS, Scopus and Google Scholar

- Research which is freely available for redistribution

Submit your manuscript at www.biomedcentral.com/submit
C Biomed Central 